\title{
Characterization of Hot Deformation Behavior of a Novel Al-Cu- Li Alloy Using Processing Maps
}

\author{
Xin-Xiang Yu ${ }^{1} \cdot$ Yi-Ran Zhang ${ }^{1} \cdot$ Deng-Feng Yin ${ }^{1,2} \cdot$ Zhi-Ming Yu$^{1} \cdot$ Shu-Fei Li ${ }^{1}$
}

Received: 18 November 2014/Revised: 20 January 2015/Published online: 27 March 2015

(C) The Chinese Society for Metals and Springer-Verlag Berlin Heidelberg 2015

\begin{abstract}
The isothermally compression deformation behavior of an elevated $\mathrm{Cu} / \mathrm{Li}$ weight ratio $\mathrm{Al}-\mathrm{Cu}-\mathrm{Li}$ alloy was investigated under various deformation conditions. The isothermal compression tests were carried out in a temperature range from 300 to $500{ }^{\circ} \mathrm{C}$ and at a strain rate range from 0.001 to $10 \mathrm{~s}^{-1}$. The results show that the peak stress level decreases with temperature increasing and strain rate decreasing, which is represented by the Zener-Hollomon parameter $Z$ in the hyperbolic sine equation with the hot deformation activation energy of $218.5 \mathrm{~kJ} / \mathrm{mol}$. At low $Z$ value, the dynamic recrystallized grain is well formed with clean high-angle boundaries. At high $Z$ value, a high dislocation density with poorly developed cellularity and considerable fine dynamic precipitates are observed. Based on the experimental data and dynamic material model, the processing maps at strain of 0.3, 0.5 and 0.7 were developed to demonstrate the hot workability of the alloy. The results show that the main softening mechanism at high $Z$ value is precipitate coarsening and dynamic recovery; the dynamic recrystallization of the alloy can be easily observed as $\ln Z \leq 29.44$, with peak efficiency of power dissipation of around $70 \%$. At strains of $0.3,0.5$ and 0.7 , the flow instability domains are found at higher strain rates, which mainly locate at the upper part of processing maps. In addition, when the strain rate is 0.001 or $0.02 \mathrm{~s}^{-1}$, there is a particular instability domain at $300-350{ }^{\circ} \mathrm{C}$.
\end{abstract}

\section{KEY WORDS: Al-Cu-Li alloy; Hot deformation behavior; Microstructure evolution; Processing maps}

\section{Introduction}

Al-Li alloys with elevated $\mathrm{Cu} / \mathrm{Li}$ weight ratio have received considerable interest from both industrial and scientific communities because of their attractive high strength to weight ratio, large elastic modulus, small anisotropy, excellent resistivity to damage and good

Available online at http://link.springer.com/journal/40195

Deng-Feng Yin

dfyin@126.com

1 School of Materials Science and Engineering, Central South University, 932 Lushan South Road, Changsha 410083, China

2 School of Engineering, Yantai Nanshan University, Yantai 265713, China weldability. These characteristics make these alloys a very attractive choice for direct and engineered substitution in all weight-critical applications, e.g., high-performance air crafts, launch vehicles and satellite structures. This material has been successfully used by NASA in space shuttle for super lightweight cryogenic tanks with significant increase in payload capacity $[1,2]$.

In the past decades, much attention has been paid to microstructure and mechanical properties of $\mathrm{Al}-\mathrm{Cu}-\mathrm{Li}$ alloys with trace amounts of $\mathrm{Ag}, \mathrm{Mg}$ and $\mathrm{Zr}$ [3-7]. However, the sheets of high-strength aluminum alloys showed low formability because of more alloy compositions and complicated microstructure transformation during high-temperature deformation. So it is necessary to investigate the deformation behavior and microstructure evolution of this type of $\mathrm{Al}$ alloy sheets during high temperature deformation to understand the deformation mechanism of the alloy. 
$\mathrm{Hu}$ et al. [8] investigated the main deformation mechanism of high-strength 7050 aluminum alloy and found that the main softening mechanism of this alloy deformation at high $Z$ value $\left(340{ }^{\circ} \mathrm{C}, 1.0 \times 10^{-2} \mathrm{~s}^{-1}\right)$ was dynamic recovery while continuous dynamic recrystallization was the primary softening mechanism when the alloy deformed at low $Z$ value $\left(460{ }^{\circ} \mathrm{C}, 1.0 \times 10^{-2}\right.$ and $1.0 \times 10^{-4} \mathrm{~s}^{-1}$ ). McQueen et al. [9] revealed that dynamic precipitation increased the initial flow stress of $\mathrm{Al}-\mathrm{Mg}-\mathrm{Si}$ alloy and resulted in shear banding and fine polygonized substructure. Cerri et al. [10] reported that pretreatment influences the hot deformation activation energy of 7075 Al alloy. The hot deformation activation energy of the precipitated alloy is close to pure aluminum but lower than the solution treated alloy. Chen et al. [11] investigated the hot deformation behavior and processing maps of 2099 alloy using hot tensile tests and found that an instability domain was obtained in the temperature and strain rate ranges: $250-260{ }^{\circ} \mathrm{C}$ and $0.1-0.5 \mathrm{~s}^{-1}$. Li et al. [12] studied the hot deformation behavior of $\mathrm{Al}-\mathrm{Cu}-\mathrm{Li}-\mathrm{Sc}-\mathrm{Zr}$ alloy and its microstructure evolution.

The processing maps were developed on the basis of dynamic material model (DMM) and had been used to design hot working schedules in a wide variety of materials [13-15]. The maps explicitly represented local peak efficiency of power dissipation, which was the response of specific microstructure mechanism and regions of flow instability. With the help of the processing maps, the deformation temperature and the strain rate corresponding to local peak efficiency of power dissipation in this domain were chosen as the optimum processing parameter for hot working of materials. The hot working should not be performed in the regions of flow instability to prevent the occurrence of microstructure-based defects.

The deformation mechanism of elevated $\mathrm{Cu} / \mathrm{Li}$ weight ratio $\mathrm{Al}-\mathrm{Cu}-\mathrm{Li}$ alloy has not yet clarified. Therefore, further investigations are needed to illustrate the deformation mechanism and optimize the processing parameters in isothermal compression of this novel $\mathrm{Al}-\mathrm{Cu}-\mathrm{Li}$ alloy using processing maps.

\section{Experimental}

The alloy with a nominal chemical composition of $\mathrm{Al}-$ $5.8 \mathrm{Cu}-1.3 \mathrm{Li}-0.4 \mathrm{Mg}-0.4 \mathrm{Ag}-0.14 \mathrm{Zr}$ (wt\%) was studied in this work. Master alloys of $\mathrm{Al}-\mathrm{Zr}, \mathrm{Al}-\mathrm{Cu}$ and pure $\mathrm{Ag}, \mathrm{Mg}$, $\mathrm{Li}$ and remainder $\mathrm{Al}$ were melted in vacuum induction melting furnace under a controlled atmosphere of argon gas, by using high pure graphite crucible. Lithium addition was made by plunging Li wrapped in aluminum foil [16]. Casting was carried out under argon. The ingots with size of $150 \mathrm{~mm} \times 100 \mathrm{~mm} \times 22 \mathrm{~mm}$ were homogenized using three-step homogenization cycle at $400{ }^{\circ} \mathrm{C} / 8 \mathrm{~h}+470{ }^{\circ} \mathrm{C} /$ $8 \mathrm{~h}+510^{\circ} \mathrm{C} / 8 \mathrm{~h}$ in a salt bath. After homogenization, the ingots were cooled slowly to room temperature in air.

Figure 1 shows the initial microstructure of the alloy. It can be seen that the microstructure of the alloy mainly consists of fine equiaxed crystal. The average grain size was determined to be about $100 \mu \mathrm{m}$.

Specimens with size of $\phi 8 \mathrm{~mm} \times 10 \mathrm{~mm}$ were machined from the homogenized alloy. Hot compression tests were performed on Gleeble 3180 testing machine. All the specimens were heated to the test temperature and held for 3 min before pressing and then were compressed at deformation temperatures of $300,350,400,450$ and $500{ }^{\circ} \mathrm{C}$ and strain rates of $0.001,0.01,0.1,1$ and $10 \mathrm{~s}^{-1}$, respectively. After deformation, all the specimens were quenched into water to freeze the deformed microstructure. After hot compression testing, the specimens were sectioned parallel to the compression axis. The microstructure observation of the alloy was carried out using optical microscopy (OM) and transmission electron microscopy (TEM). Specimens for OM observation were polished and etched in a solution containing $1 \% \mathrm{HF}, 1.5 \% \mathrm{HCl}$ and $3 \% \mathrm{HNO}_{3}$ at room temperature. Specimens for TEM examination were cut from the gauge section of the deformed specimens, thinned to about $0.1 \mathrm{~mm}$, and finally electropolished by the solution of $30 \% \mathrm{HNO}_{3}+70 \% \mathrm{CH}_{3} \mathrm{OH}$ below $-25{ }^{\circ} \mathrm{C}$. TEM observations were performed by using Tecnai $\mathrm{G}^{2} 20$ transmission electron microscope operated at $200 \mathrm{kV}$. The microstructure after homogenization was examined on Sirion 200 scanning electron microscope (SEM).

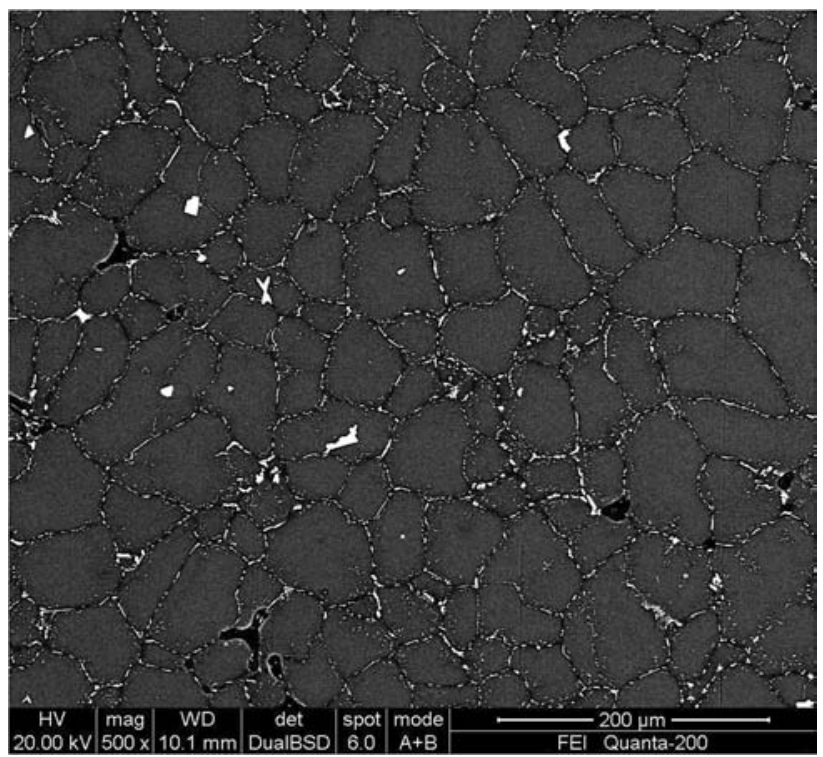

Fig. 1 Microstructure of the experimental alloy after homogenization treatment 


\section{Results and Discussion}

\subsection{Flow Stress}

Based on the experimental data, the true stress-true strain curves in isothermal compression of the alloy at different deformation temperatures and strain rates are depicted in Fig. 2. It is found that the general characteristics of these curves are basically similar to each other at all deformation conditions. The flow stress increases sharply with increasing strain in the early stage and then reaches a peak value. After the peak flow stress, the flow stress decreases gradually and then keeps at a steady value. However, the flow stress declined with deformation temperature increasing and strain rate decreasing. At strain rate of $0.001 \mathrm{~s}^{-1}$, high temperature of 450 and $500{ }^{\circ} \mathrm{C}$, an oscillation in the flow stress-strain curves was observed, which should be a typical phenomenon showing partial dynamic recrystallization [17].

According to the curves in Fig. 2, the stresses soften amplitude $(\Delta \sigma)$ of the alloy at different deformation temperatures and strain rates can be determined by

$\Delta \sigma=\sigma_{\mathrm{p}}-\sigma_{0.7}$

where $\sigma_{\mathrm{p}}$ is the peak stress for the alloy, $\sigma_{0.7}$ is the stress for the alloy when strain at 0.7 .

Figure 3 shows the calculated $\Delta \sigma$ of the alloy at different deformation temperatures and strain rates. It can be

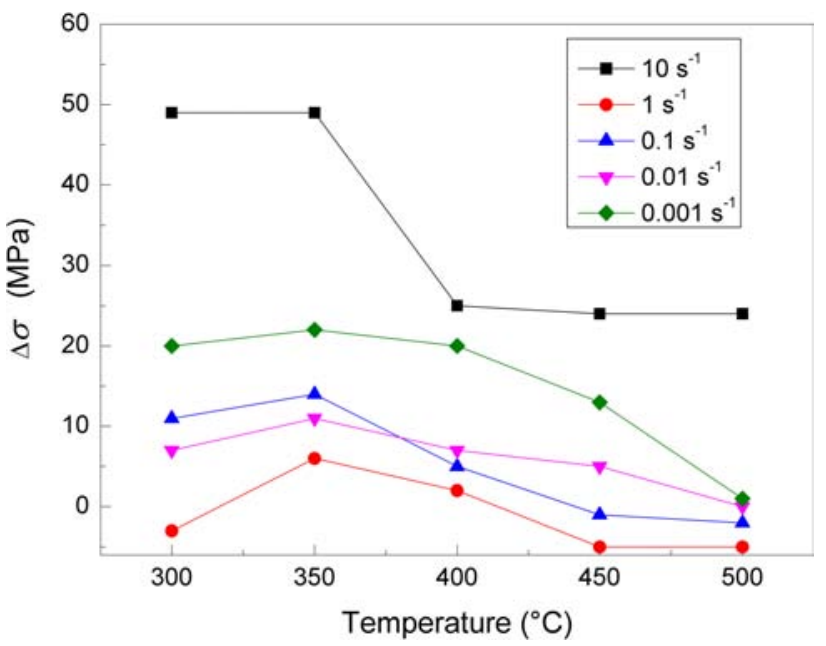

Fig. 3 Stresses soften amplitude $(\Delta \sigma)$ of the alloy at different deformation temperatures and strain rates

found that the soften amplitude is significant at both low strain rate $\left(0.001 \mathrm{~s}^{-1}\right)$ and high strain rate $\left(10 \mathrm{~s}^{-1}\right)$. At the strain rate of $10 \mathrm{~s}^{-1}$, the $\Delta \sigma$ decreases rapidly with increasing temperatures from 350 to $400{ }^{\circ} \mathrm{C}$. It then remains stable with a further increase in the temperature. At strain rate of $1-0.01 \mathrm{~s}^{-1}$, deformation temperature seems to have little influence on $\Delta \sigma$. However, at the strain rate of $0.001 \mathrm{~s}^{-1}$, the $\Delta \sigma$ decreases rapidly with increasing deformation temperatures from 400 to $500{ }^{\circ} \mathrm{C}$. (a)

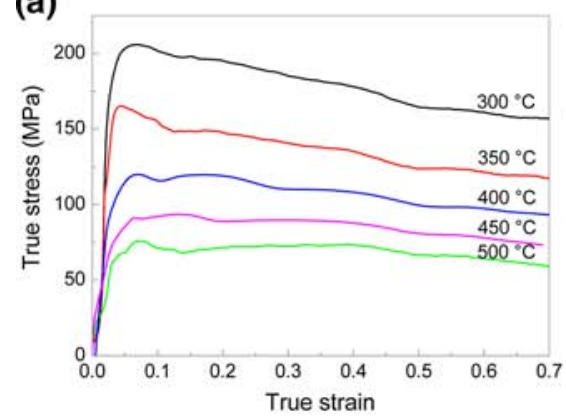

(d)

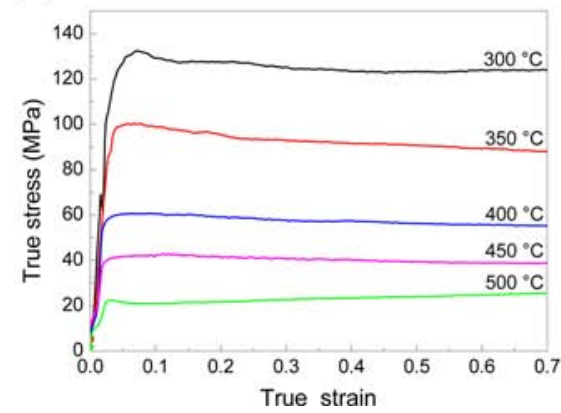

(b)

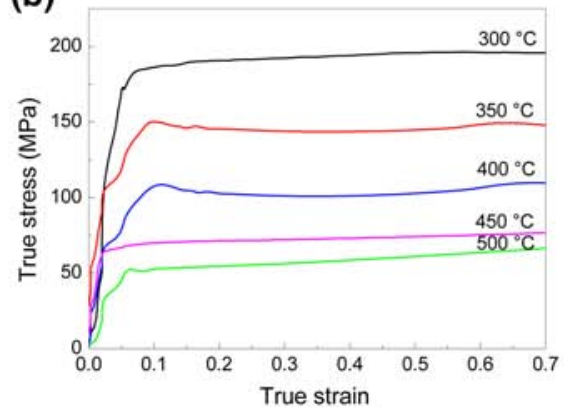

(e)

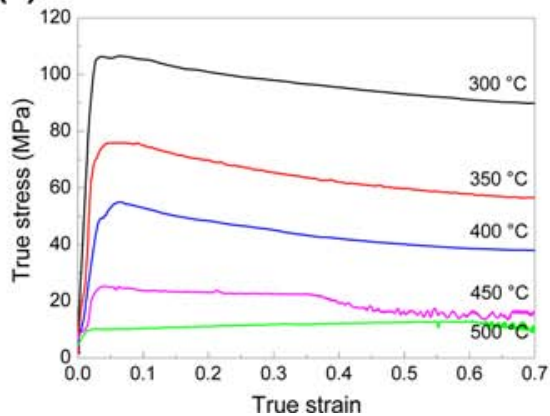

(c)

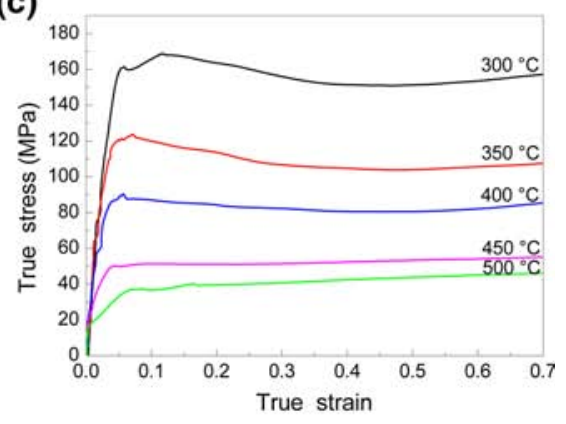

Fig. 2 Typical true stress-true strain curves of the experimental specimen under deformation strain rates: a $10 \mathrm{~s}^{-1}$; b $1 \mathrm{~s}^{-1}$; c $0.1 \mathrm{~s}^{-1}$; d $0.01 \mathrm{~s}^{-1} ; \mathbf{e} 0.001 \mathrm{~s}^{-1}$ 


\subsection{Constitutive Analysis}

In hot working, several constitutive equations have commonly been applied, as following [18]:

$\dot{\varepsilon}=A_{1} \sigma^{n 1} \exp \left(\frac{-Q}{R T}\right)$,

$\dot{\varepsilon}=A_{2} \exp (\beta \sigma) \exp \left(\frac{-Q}{R T}\right)$,

$\dot{\varepsilon}=A(\sinh \alpha \sigma)^{n} \exp \left(\frac{-Q}{R T}\right)$,

where $\alpha$ is the stress multiplier; $A_{1}, A_{2}, A, n_{1}, n$ and $\beta$ are the material constants; $\alpha=\beta / n_{1} ; R$ is the universal gas constant $\left(8.314 \mathrm{~J} \mathrm{~mol}^{-1} \mathrm{~K}^{-1}\right) ; T$ is the absolute temperature $(K) ; Q$ is the deformation activation energy $(\mathrm{J} / \mathrm{mol}) ; \sigma$ is often taken as peak flow stress or steady state stress. Equations (2) and (3) break at a low stress and at a high stress, respectively. The hyperbolic sine law Eq. (4) is a more general form suitable for over a wide range [19].

Taking natural logarithm on both sides of Eqs. (2), (3) and (4), they can be expressed as

$\ln \dot{\varepsilon}=\ln A_{1}+n_{1} \ln \sigma-Q / R T$,
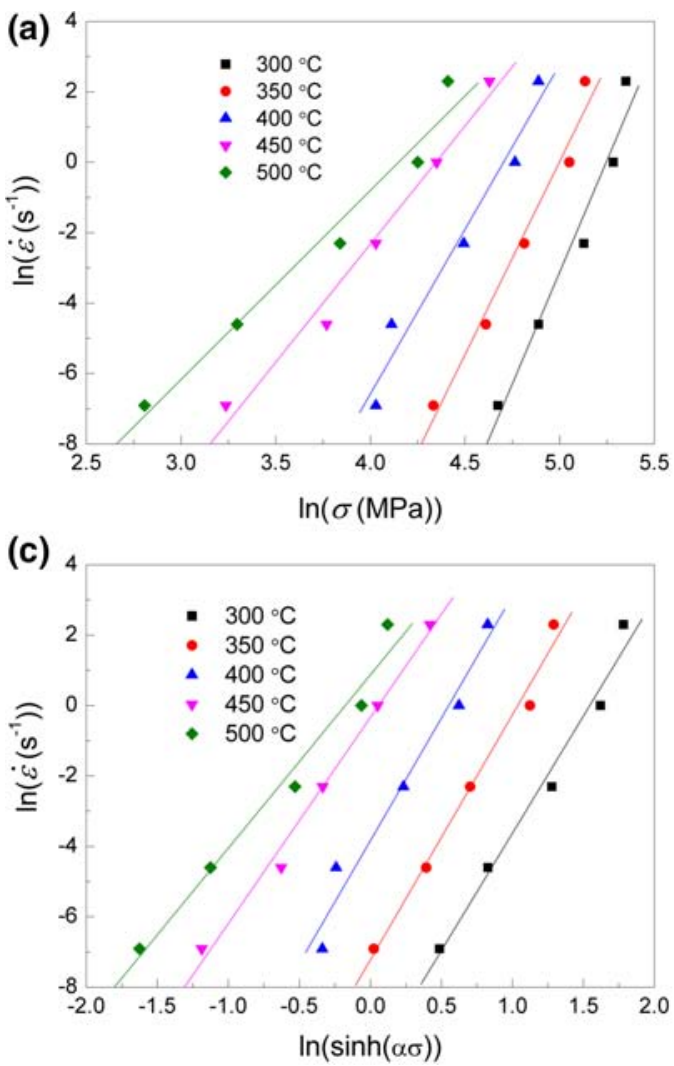

$\ln \dot{\varepsilon}=\ln A_{2}+\beta \sigma-Q / R T$,

$\ln \dot{\varepsilon}=\ln A+n \ln [\sinh (\alpha \sigma)]-Q / R T$.

Figure 4 shows the relationships between $\ln \dot{\varepsilon}$ and $\ln \sigma$, $\ln \dot{\varepsilon}$ and $\sigma, \ln \dot{\varepsilon}$ and $\ln [\sinh (\alpha \sigma)]$, and $\ln [\sinh (\alpha \sigma)]$ and 1000/ T. From Fig. $4 \mathrm{a}, \mathrm{b}, n_{1}, \beta$ can be obtained by linear regression method, which are the slopes of the curves of $\ln \dot{\varepsilon}$ versus $\ln \sigma$ and $\ln \dot{\varepsilon}$ versus $\sigma$, respectively, at various strains. Using the same method, $n$ and $Q$ can be obtained from Fig. 4c, d, respectively.

The high-temperature deformation behavior of materials is represented by the Zener-Hollomon parameter $(Z)$, which correlates the strain rate, deformation temperature and activation energy by the following expression:

$Z=\dot{\varepsilon} \exp \left(\frac{Q}{R T}\right)$

The values of $Z$ at various strain rates and deformation temperatures can be calculated by Eq. (8) and are listed in Table 1.

Combining Eqs. (4) and (8), the expression for $Z$ is obtained as

$Z=\dot{\varepsilon} \exp \left(\frac{Q}{R T}\right)=A[\sinh (\alpha \sigma)]^{n}$

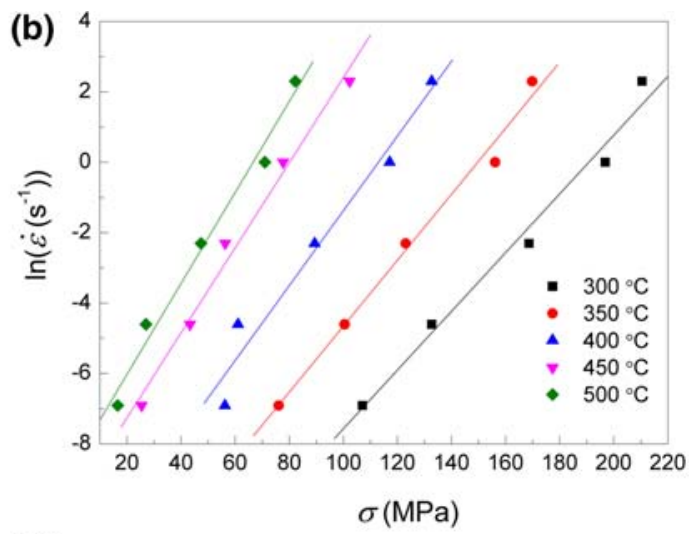

(d)

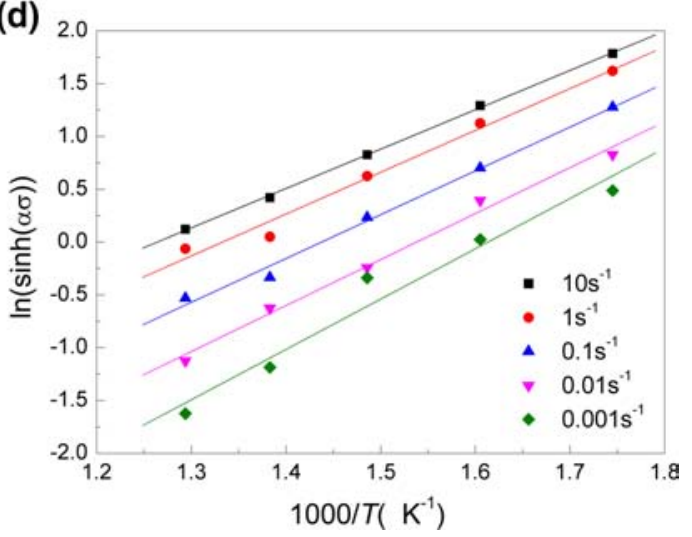

Fig. 4 Relationships between $\ln \dot{\varepsilon}$ and $\ln \sigma$ a, $\ln \dot{\varepsilon}$ and $\sigma \mathbf{b}, \ln \dot{\varepsilon}$ and $\ln (\sinh (\alpha \sigma)) \mathbf{c}, \ln (\sinh (\alpha \sigma))$ and $1000 / T$ d 
Table 1 Values of $\ln Z$ under different deforming conditions

\begin{tabular}{llllll}
\hline$\dot{\varepsilon}\left(\mathrm{s}^{-1}\right)$ & \multicolumn{5}{l}{ Temperature $\left({ }^{\circ} \mathrm{C}\right)$} \\
\cline { 2 - 6 } & 300 & 350 & 400 & 450 & 500 \\
\hline 10 & 48.17 & 44.49 & 41.36 & 38.65 & 36.30 \\
1 & 45.88 & 42.19 & 39.05 & 36.35 & 34.00 \\
0.1 & 43.57 & 39.88 & 36.75 & 34.05 & 31.70 \\
0.01 & 41.26 & 37.58 & 34.45 & 31.75 & 29.39 \\
0.001 & 38.96 & 35.28 & 32.14 & 29.44 & 27.09 \\
\hline
\end{tabular}

Taking natural logarithm from both sides of Eq. (9) yields

$\ln Z=\ln A+n \ln [\sinh (\alpha \sigma)]$.

Figure 5 shows the relation between $\ln Z$ and $\ln [\sinh (\alpha \sigma)]$. From Fig. 5, $\ln A$ can be obtained, which is the intercept, and $n$ is the slope of $\ln Z-\ln [\sinh (\alpha \sigma)]$, which is obtained also.

The material constants of the alloy obtained from the experimental data are listed in Table 2. The hot deformation activation energy derived from Arrhenius plots of $\ln$ $\sinh (\alpha \sigma)$ versus $1000 / T$ as shown in Fig. $4 d$ is $218.51 \mathrm{~kJ} / \mathrm{mol}$ for the studied alloy, which is slight lower than that of the solid solution treated 7050 aluminum alloy $(256.6 \mathrm{~kJ} / \mathrm{mol})$ reported by $\mathrm{Hu}$ et al. [8], but much more than the value of a furnace-cooled 7050 aluminum alloy after homogenization treated $\left(465{ }^{\circ} \mathrm{C} / 24 \mathrm{~h}+475^{\circ} \mathrm{C} / 4 \mathrm{~h}\right)$ and deformed at the true strain of $0.7(170 \mathrm{~kJ} / \mathrm{mol})$ reported by Liu et al. [20].

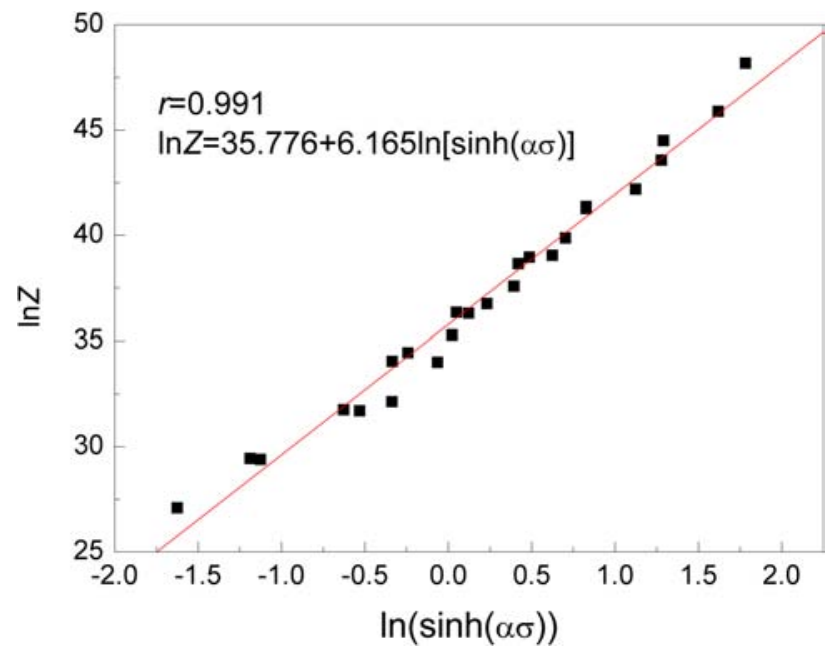

Fig. 5 Linear relationship between $\ln Z$ and $\ln [\sinh (\alpha \sigma)]$

Table 2 Material constants and $Q$ value of the experimental alloy

\begin{tabular}{llll}
\hline$\alpha\left(\mathrm{MPa}^{-1}\right)$ & $A\left(\mathrm{~s}^{-1}\right)$ & $n$ & $Q(\mathrm{~kJ} / \mathrm{mol})$ \\
\hline 0.0118 & $3.446 \times 10^{15}$ & 6.27 & 218.51 \\
\hline
\end{tabular}

Based on the experimental results, the constitutive equations that describe the flow stress as a function of strain rate and deformation temperature for the alloy can be written as

$\dot{\varepsilon}=3.446 \times 10^{15}[\sinh (0.0118)]^{6.27} \exp \left(-\frac{218.51}{8.314 T}\right)$.

\subsection{Processing Maps}

According to the dynamic material modeling, the total energy absorbed by the deformation workpiece in the process of hot deformation dissipates mainly through the following two aspects: consumption in plastic deformation and structural transformation. So the total energy $P$ absorbed by the object can be determined as two complementary functions: $G$ and $J$ [21-23].

$P=\sigma \dot{\varepsilon}=G+J=\int_{0}^{\dot{\varepsilon}} \sigma \mathrm{d} \dot{\varepsilon}+\int_{0}^{\sigma} \dot{\varepsilon} \mathrm{d} \sigma$

where $G$ term refers to the power consumed in plastic deformation, most of which is converted into viscoplastic heat. The term $J$ is related to the power consumed in structural transformation such as dynamic recovery, dynamic recrystallization, internal fracture (void formation or wedge cracking), deformation-induced phase transformation and precipitation under dynamic conditions. The flow stress and strain rate sensitivity $m$ can be expressed as

$\sigma=K(\dot{\varepsilon})^{m}$

where $K$ is a parameter that only depends upon the structure of the material and temperature, and $m$ is strain rate sensitivity. Given a constant strain and deformation temperature, the value of $m$ can be deduced as

$m=\left|\frac{\partial \ln \sigma}{\partial \ln \dot{\varepsilon}}\right|_{\varepsilon, T}$.

So the ratio between $G$ and $J$ can be determined by the strain rate sensitivity $m$ as

$\Delta J / \Delta G \approx m$,

$\Delta J / \Delta P \approx m /(m+1)$.

For an ideal linear dissipater, $m=1$, so $(\Delta J / \Delta P)_{\text {line }} \approx m /(m+1)=1 / 2$.

In order to determine the proportion of the energy consumed in structural transformation, the parameter $\eta$ is used to describe the efficiency of power dissipation. It is determined as

$\eta=\frac{J}{J_{\max }}=\frac{\Delta J / \Delta P}{(\Delta J / \Delta P)_{\text {line }}}=\frac{m /(m+1)}{1 / 2}=\frac{2 m}{m+1}$,

where $\eta$ is the efficiency of power dissipation, determined by $\varepsilon, \dot{\varepsilon}, T$. When strain is a constant, $\eta$ is determined by 
strain rate and temperature in the processing efficiency maps; larger value indicates that the proportion of the power dissipated by microstructure evolution increases with the increase of $\eta$.

Figure 6 shows the effects of strain rates and deformation temperatures on $\eta$ of the studied alloy at strains of 0.3 , 0.5 and 0.7. As shown in Fig. 6, $\eta$ increased with decreasing strain rate, and the peak values of $\eta$ are 70,60 and $50 \%$ for strains of $0.3,0.5$ and 0.7 , respectively. In the processing efficiency maps, larger $\eta$ value indicates that the proportion of the energy consumed in structural transformation is greater; thus, in general, the material shows a good workability when the specimen deformed in the domain with high efficiency of power dissipation.

However, the value of power dissipation efficiency may be also high when the processing condition is in an instability domain. At this time, processing efficiency maps cannot really reflect the processing property, so additional processing instability maps is necessary. An instability criterion based on the extremism principles of irreversible thermodynamic as applied to plastic flow is used to identify the regimes of flow instabilities which could be derived by Prasad criterion $[24,25]$ can be expressed as

$\xi(\dot{\varepsilon})=\frac{\partial \log (m /(m+1))}{\partial \lg \dot{\varepsilon}}+m<0$.

The variation of instability parameter $\xi(\dot{\varepsilon})$ may be evaluated as a function of deformation temperature and strain rate to obtain an instability map, where metallurgical instability during plastic flow occurs in regimes where $\xi(\dot{\varepsilon})$ is negative.

It is evident that the processing map is very beneficial for optimizing hot workability and controlling microstructure in the strains of $0.3,0.5$ and 0.7 , respectively. Figure 7 shows the processing maps of the alloy, which are constructed in strain rate range from 0.001 to $10 \mathrm{~s}^{-1}$ and deformation temperature range from 300 to $500{ }^{\circ} \mathrm{C}$. The contour numbers represent the efficiency of power dissipation, and shaded areas represent the instability regions. The values of $\eta$ and the instability region at different deformation temperatures and strain rates can be obtained based on Eqs. (17) and (18). It is observed from Fig. 7 that the efficiency of power dissipation increases with decreasing strain rates. The instability domain is found at high strain rates, which mainly locates at the upper part of processing maps. The instability region which mainly locates at the upper part of processing maps gradually moves to condition of high temperature and low strain rate with increasing of strain which indicate that the effect of strain on the processing maps is significant. In addition, there is a particular instability domain at a temperature ranges from 300 to $350{ }^{\circ} \mathrm{C}$ and a strain rate range from 0.001 to $0.02 \mathrm{~s}^{-1}$. To our knowledge, this has not been reported in $\mathrm{Al}-\mathrm{Cu}-\mathrm{Li}-\mathrm{Sc}-\mathrm{Zr}$ alloy [12], $2099 \mathrm{Al}$ alloy [11] and also $7050 \mathrm{Al}$ alloy [26]. A detailed description of unsafe processing domains is shown in Table 3.

The processing maps at a strain of $0.3,0.5$ and 0.7 all exhibit the same domain with high efficiency of power dissipation, which is in the deformation temperature range from 450 to $500{ }^{\circ} \mathrm{C}$ and the strain rates below $0.003 \mathrm{~s}^{-1}$ with a peak efficiency above 0.5 at $475{ }^{\circ} \mathrm{C}$ and $0.0015 \mathrm{~s}^{-1}$. The microstructure corresponding to the peak efficiency of above 0.5 is shown in Fig. 7c. It is well known that DRX is beneficial to grain refinement and improvement of the intrinsic workability of material [26]. Therefore, the optimal processing parameter of high $\mathrm{Cu} / \mathrm{Li} \mathrm{Al}-\mathrm{Cu}-\mathrm{Li}$ alloy at a strain of 0.7 corresponds to a deformation temperature of $475{ }^{\circ} \mathrm{C}$ and strain rate of $0.0015 \mathrm{~s}^{-1}$.

\subsection{Microstructure}

Figure 8 shows the microstructure of the alloys after homogenization treatment and hot deformation at temperature of $300{ }^{\circ} \mathrm{C}$ and strain rate of $10 \mathrm{~s}^{-1}$, respectively. Many plate-shaped particles are observed before and after hot deformation. According to EDS analysis and the reported results [3], it is proposed that these particles are $\mathrm{T} 1\left(\mathrm{Al}_{2}\right.$ $\mathrm{CuLi}$ ) phase that is hard to nucleate and through the introduction of dislocations. These dislocations normally act as preferential matrix nucleation sites for the primary strengthening phase $\mathrm{T} 1$ [27]. The width of $\mathrm{T} 1$ phases in Fig. 8a has size of $300-400 \mathrm{~nm}$ and $0.7-3 \mu \mathrm{m}$, while it is (a)

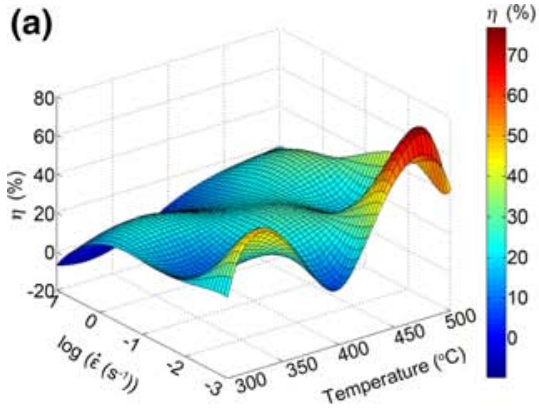

(b)

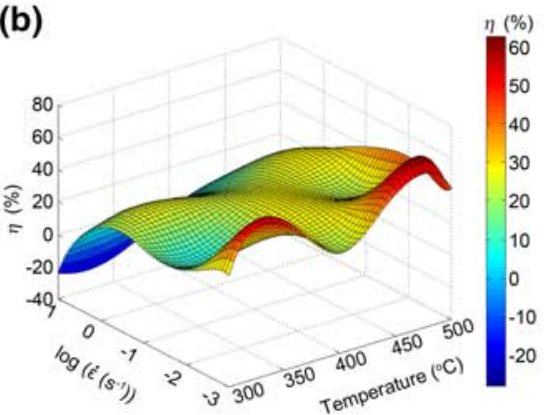

(c)

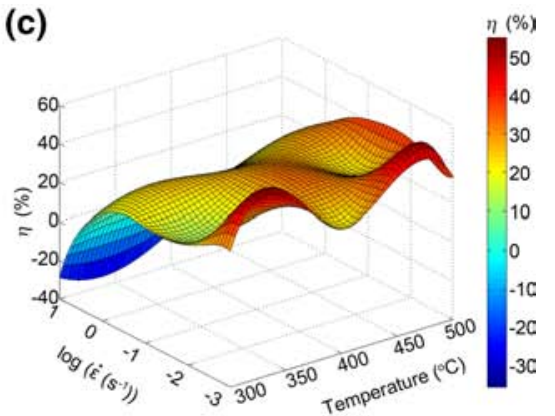

Fig. 6 Power dissipation maps from the hot compression at various strains of 0.3 a, $0.5 \mathbf{b}, 0.7$ c 

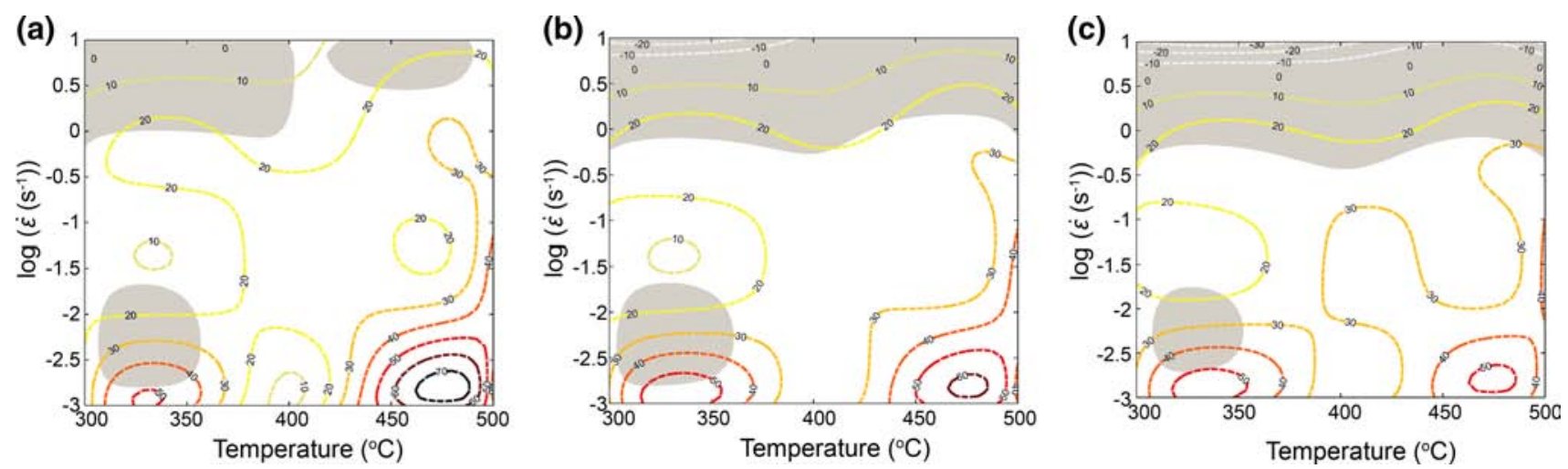

Fig. 7 DMM processing maps of the experimental alloy at various strains of $0.3 \mathbf{a}, 0.5 \mathbf{b}, 0.7 \mathbf{c}$

Table 3 Ranges of temperature and strain rate for unsafe processing domains under different strains

\begin{tabular}{lcc}
\hline Strain & Temperature $\left({ }^{\circ} \mathrm{C}\right)$ & Strain rate $\left(\mathrm{s}^{-1}\right)$ \\
\hline 0.3 & $300-400$ & $1-10$ \\
& $420-490$ & $3.162-10$ \\
& $306-356$ & $0.0016-0.02$ \\
0.5 & $300-500$ & $0.631-10$ \\
& $303-360$ & $0.0016-0.02$ \\
0.7 & $300-500$ & $0.355-10$ \\
& $308-352$ & $0.0022-0.0178$ \\
\hline
\end{tabular}

just about $50 \mathrm{~nm}$ for the alloy after hot deformation at temperature of $300{ }^{\circ} \mathrm{C}$ and strain rate of $10 \mathrm{~s}^{-1}$ (Fig. 8b). Furthermore, the amount of $\mathrm{T} 1$ phases increased simultaneously after hot deformation $\left(300{ }^{\circ} \mathrm{C}, 10 \mathrm{~s}^{-1}\right)$. So it is deduced that dynamic precipitation and precipitates coursing occurred during hot deformation at low temperature and high strain rate.

The optical microstructures of this high $\mathrm{Cu} / \mathrm{Li} \mathrm{Al}-\mathrm{Cu}-\mathrm{Li}$ alloy after isothermal compression are given in Fig. 9. It can be seen from Fig. 9a-d that the microstructure in the instability region of the present experimental alloy mainly consists of $\alpha-\mathrm{Al}$ matrix with elongated grains. By the analysis of the processing maps and microstructural evolution, it is confirmed that the dynamic recovery is the dominant softening mechanism at the deformation temperature below $450{ }^{\circ} \mathrm{C}$ in the whole strain rate range, and at the deformation temperature above $450{ }^{\circ} \mathrm{C}$ and high strain rate higher than $1.0 \mathrm{~s}^{-1}$. At a deformation temperature of $500{ }^{\circ} \mathrm{C}$ and strain rate of $0.001 \mathrm{~s}^{-1}$, fine and equiaxed grains are observed along the elongated grain boundaries and the grain interior (see Fig. 9e). The microstructural observation illustrates that the softening mechanism is continuous dynamic recrystallization at a deformation temperature above $450{ }^{\circ} \mathrm{C}$ and the strain rates below $1 \mathrm{~s}^{-1}$. At higher deformation temperature, the diffusion abilities of atoms, cross-slip of dislocation and migration of grain boundaries are enhanced, which are beneficial to the nucleation and nucleus growth of DRX. The steady flow stress-strain curves in the form of serrate at the strain rates of $0.001 \mathrm{~s}^{-1}$ are also in support of this deformation
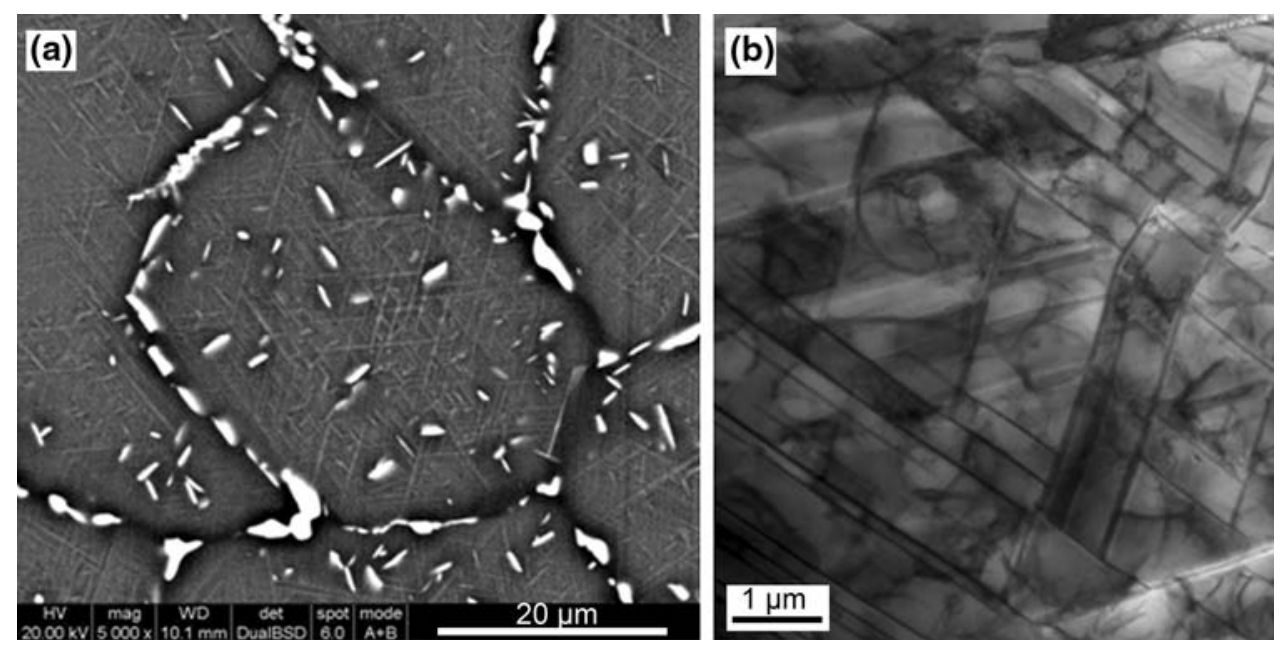

Fig. 8 a SEM image of the alloy after homogenization treatment. b TEM image of the alloy after hot deformation at temperature of $300{ }^{\circ} \mathrm{C}$ and strain rate of $10 \mathrm{~s}^{-1}$ 

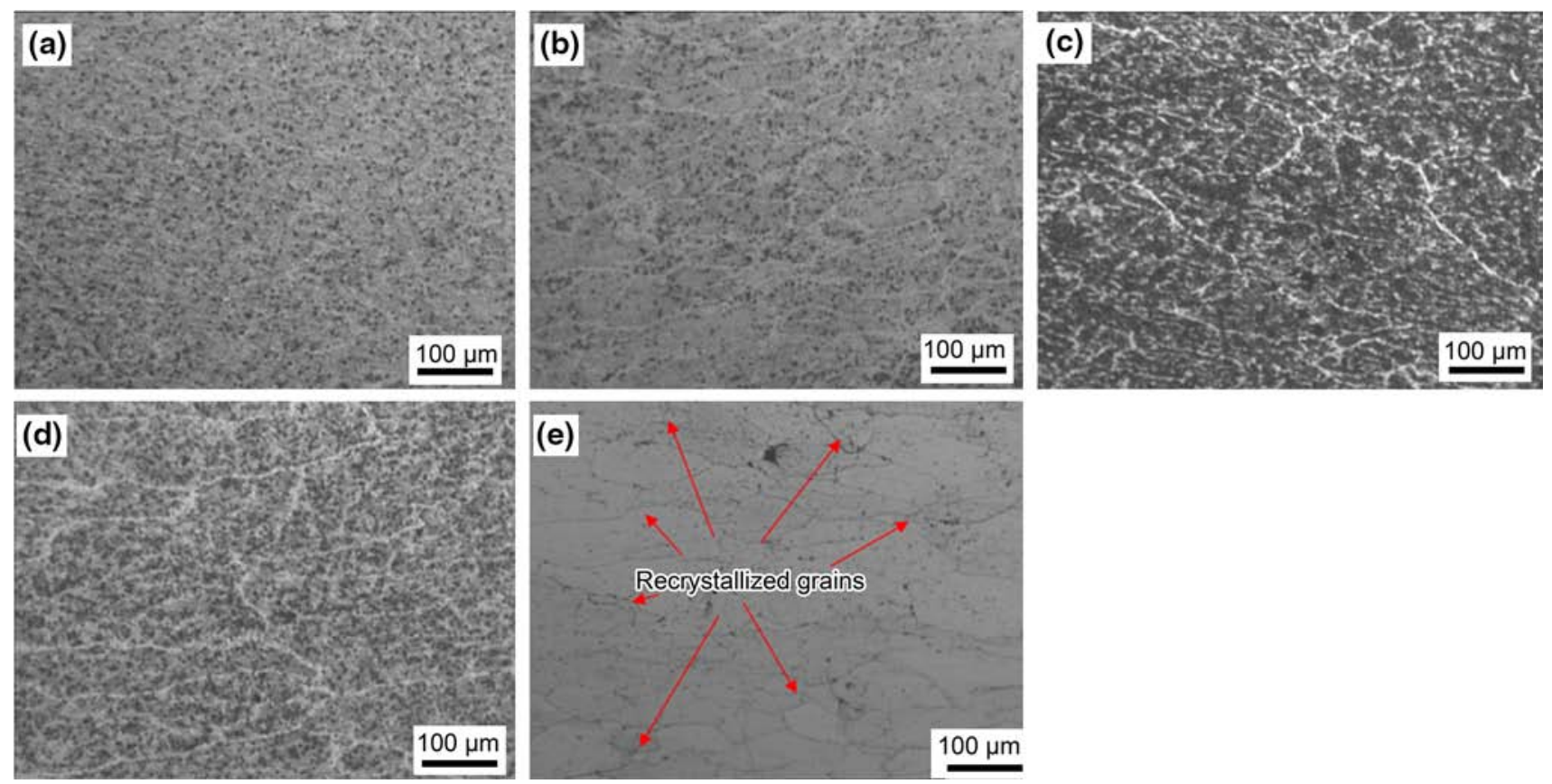

Fig. 9 Optical microscopy images of specimens deformed under different temperatures and at different strain rates: a $300{ }^{\circ} \mathrm{C}, 10 \mathrm{~s}^{-1} ; \mathbf{b} 350{ }^{\circ} \mathrm{C}$, $1 \mathrm{~s}^{-1} ;$ c $400{ }^{\circ} \mathrm{C}, 0.1 \mathrm{~s}^{-1} ; \mathbf{d} 450{ }^{\circ} \mathrm{C}, 0.01 \mathrm{~s}^{-1}$; e $500{ }^{\circ} \mathrm{C}, 0.001 \mathrm{~s}^{-1}$

mechanism, as illustrated in Fig. 2e, which is a typical phenomenon showing partial dynamic recrystallization [17]. Deformation temperatures and strain rates have a significant influence on microstructure evolution [12, 28].

Figure 10 shows the TEM images of the specimens deformed at different temperatures and strain rates. At the relatively low deformation temperature, there are a number of precipitates in the $\mathrm{Al}$ matrix of the specimen deformed at $300{ }^{\circ} \mathrm{C}$ with strain rate of $10 \mathrm{~s}^{-1}$. Interaction between these precipitates and dislocations is obvious as dislocation tangle is observed (Fig. 10a). This is because that the dislocation density and the accumulated energy increase at higher strain rates, and there is no more time for dislocation annihilation [29]. As further hot compression deformation was carried out, the dislocations reorganized through climbing and sliding, which led to a slight decreasing in dislocation density and the formation of the dislocation wall (Fig. 10b). The dislocation wall segmented the grains and the substructure formed, and the dynamic recovery occurred; when deformation temperature increased, the sufficient migration of metallic atoms and dislocations led to the merging of some small-angle sub-grain boundaries (Fig. 10c) and the low-angle grain boundaries transformed into high-angle grain boundaries through absorbing dislocations [30, 31]. At a higher deformation temperature of $450{ }^{\circ} \mathrm{C}$, the grain boundaries became straight and clear, and the dynamic recrystallized grains increased through the migration of dislocations and high-angle grain boundaries (Fig. 10d).

In the beginning of deformation, it is believed that strain hardening, precipitation hardening, solid solution hardening and structural softening processes may be superimposed. The flow stress of the alloy varies with different deformation
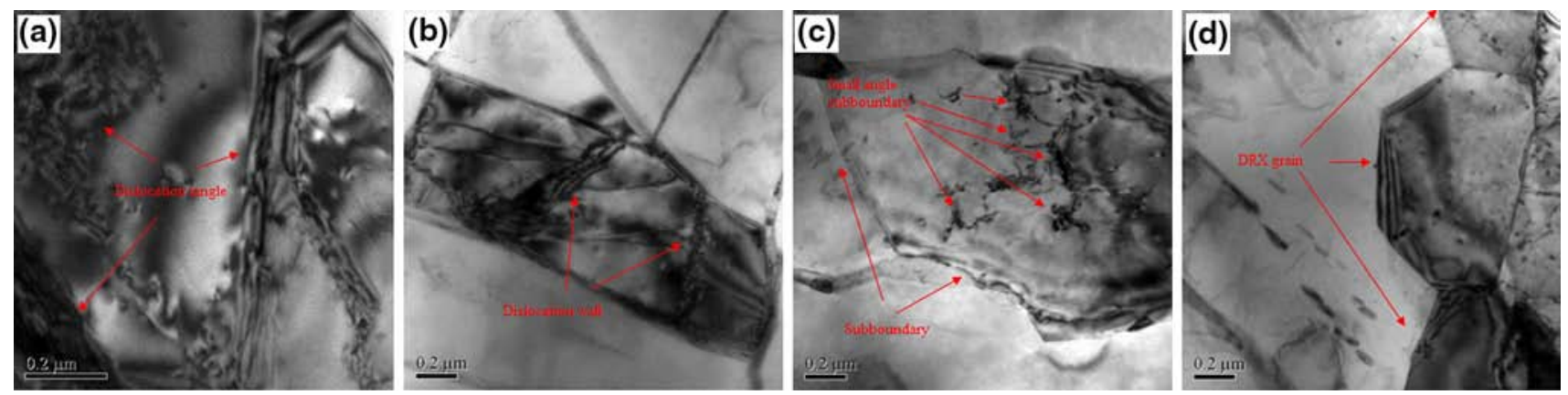

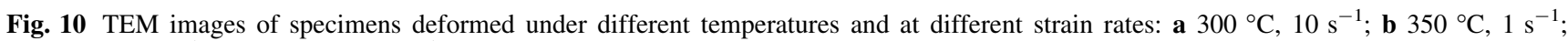
c $400{ }^{\circ} \mathrm{C}, 0.1 \mathrm{~s}^{-1} ; \mathbf{d} 450{ }^{\circ} \mathrm{C}, 0.001 \mathrm{~s}^{-1}$ 
conditions. Comparing to low strain rate alloy where the net formation of dislocation was relatively low, there was nucleation of second phase takes place with accelerated kinetics during deformation, due to high density of dislocations forming during deformation at $10 \mathrm{~s}^{-1}$. These newly formed fine particles will retard the motion of dislocations very effectively and inhibit recovery as well. But this effect will decrease and become negligible as precipitation coarsening with strain increasing. However, at high deformation temperature, most of the supersaturated solid solution was exhausted, and the primary precipitates were coarsening considerably during the period of heating and isothermal holding before hot compression (Fig. 2a). At strain rate of $1-0.01 \mathrm{~s}^{-1}$, on the one hand, the newly formed fine precipitates were very little and there was only precipitate coarsening quickly, which results in fewer solutes in the solid solution, thus the weaker the solid solution strengthening. At the same time, dynamic recovery may occur easily when strain rate is lower $\left(1-0.01 \mathrm{~s}^{-1}\right)$; thus, the flow softening behavior is balanced with work hardening at this condition (Fig. 2b-d), while significant softening was also observed for alloys with strain rate decreasing to $0.001 \mathrm{~s}^{-1}$ (Fig. 2e). This is possibly due to sufficient time for occurrence of dynamic recovery and dynamic recrystallization during hot deformation. The results are in accordance with stresses soften amplitude $(\Delta \sigma)$ of the alloy at different deformation temperatures and strain rates (as shown in Fig. 3).

\section{Conclusions}

(1) The peak stress level decreases with increasing deformation temperature and decreasing strain rate; the hot deformation activation energy for the experimental alloy $(\mathrm{Al}-5.8 \mathrm{Cu}-1.3 \mathrm{Li}-0.4 \mathrm{Mg}-0.4 \mathrm{Ag}-$ $0.14 \mathrm{Zr}$ ) is $218.5 \mathrm{~kJ} / \mathrm{mol}$.

(2) At low $Z$ value, the DRX grain remains well formed with clean high-angle boundaries. At high $Z$ value, a high dislocation density with poorly developed cellularity and considerable fine dynamic precipitates are observed.

(3) The main softening mechanism at high $Z$ value is precipitate coarsening and dynamic recovery. The dynamic recrystallization of the alloy can be easily observed as $\ln Z \leq 29.44$, with peak efficiency of power dissipation of around $70 \%$.

(4) At strains of $0.3,0.5$ and 0.7 , the flow instability domains are found at higher strain rates that mainly locate at the upper part of processing maps. A particular instability domain at $300-350{ }^{\circ} \mathrm{C} / 0.001$ and $0.02 \mathrm{~s}^{-1}$ was found.
Acknowledgments This work was financially supported by the Foundation for Science and Technology Development Project of Shandong (No. 2014GGX102006).

\section{References}

[1] V. Araullo-Peters, B. Gault, F. DeGeuser, A. Deschamps, J.M. Cairney, Acta Mater. 66, 199 (2014)

[2] N. Nayan, N. Murty, A.K. Jha, B. Pant, S.C. Sharma, K.M. George, G.V.S. Sastry, Mater. Sci. Eng., A 576, 21 (2013)

[3] X.X. Yu, Z.M. Yu, D.F. Yin, H. Wang, A.Q. He, F. Cui, Rare Metal Mater. Eng. 43, 495 (2014). (in Chinese)

[4] K.S. Kumar, F.H. Heubaum, Acta Mater. 45, 2317 (1996)

[5] G. Itoh, Q. Cui, M. Kanno, Mater. Sci. Eng., A 211, 128 (1996)

[6] Z.R. Pan, Z.Q. Zheng, Z.Q. Liao, Mater. Lett. 64, 942 (2010)

[7] B. Gault, F.D. Geuser, L. Bourgeois, Ultramicroscopy 111, 207 (2011)

[8] H.E. Hu, L. Zhen, L. Yang, W.Z. Shao, B.Y. Zhang, Mater. Sci. Eng., A 488, 64 (2008)

[9] H.J. McQueen, X. Xia, Y. Cui, B. Li, Q. Meng, Mater. Sci. Eng., A 319, 420 (2001)

[10] E. Cerri, E. Evangelista, A. Forcellese, H. McQueen, Mater. Sci. Eng., A 197, 181 (1995)

[11] B. Chen, X.L. Tian, X. Li, C. Lu, J. Mater. Eng. Perform. 23, 1929 (2014)

[12] B. Li, Q.L. Pan, Z.M. Yin, Mater. Sci. Eng., A 614, 199 (2014)

[13] P.S. Robi, U.S. Dixit, J. Mater. Process. Technol. 142, 289 (2003)

[14] M. Rajamuthamilselvan, S. Ramanathan, J. Alloys Compd. 509, 948 (2011)

[15] H.Z. Li, H.J. Wang, X.P. Liang, H.T. Liu, Y. Liu, X.M. Zhang, Mater. Sci. Eng., A 528, 1548 (2011)

[16] X.X. Yu, D.F. Yin, Z.M. Yu, J. Wang, F. Cui, Rare Metal Mater. Eng. 43, 1061 (2014). (in Chinese)

[17] H.Z. Li, Z. Li, M. Song, X.P. Liang, F.F. Guo, Mater. Des. 31, 2171 (2010)

[18] S. Banerjee, P.S. Robi, A. Srinivasan, L.P. Kumar, Mater. Sci. Eng., A 527, 2498 (2010)

[19] H. Dehghan, S.M. Abbasi, A. Momeni, A. KarimiTaheri, J. Alloys Compd. 564, 13 (2013)

[20] S.D. Liu, J.H. You, X.M. Zhang, Y.L. Deng, Y.B. Yuan, Mater. Sci. Eng., A 527, 1200 (2010)

[21] Y.C. Lin, L.T. Li, Y.C. Xia, Y.Q. Jiang, J. Alloys Compd. 550, 438 (2013)

[22] M. Srinivasan, C. Loganathan, R. Narayanasamy, V. Senthilkumar, Q.B. Nguyen, M. Gupta, Mater. Des. 47, 449 (2013)

[23] A. Łukaszek-Sołek, Acta Metall. Sin. (Engl. Lett.) 28, 22 (2015)

[24] Y.Q. Ning, Z.K. Yao, H.Z. Guo, M.W. Fu, J. Alloys Compd. 584, 494 (2014)

[25] A. Momeni, K. Dehghani, Mater. Sci. Eng., A 528, 1448 (2011)

[26] J. Luo, M.Q. Li, B. Wu, Mater. Sci. Eng., A 530, 559 (2011)

[27] B.M. Gable, A.W. Zhu, A.A. Csontos, E.A. Starke Jr, J. Light Met. 1, 1 (2001)

[28] J.B. Jia, K.F. Zhang, L.M. Liu, F.Y. Wu, J. Alloys Compd. 600, 215 (2014)

[29] L. Li, X.M. Zhang, Mater. Sci. Eng., A 528, 1396 (2011)

[30] X.D. Huang, H. Zhang, Y. Han, W.X. Wu, J.H. Chen, Mater. Sci. Eng., A 527, 485 (2010)

[31] X.Y. Liu, Q.L. Pan, Y.B. He, W.B. Li, Z.M. Yin, Mater. Sci. Eng., A 500, 150 (2009) 